\title{
Development and validation of a clinical score to estimate progression to severe or critical state in Covid-19 pneumonia hospitalized patients
}

\section{Francisco Gude}

Hospital Clínico Universitario de Santiago de Compostela https://orcid.org/0000-0002-9681-1662

\section{Luis Valdés}

Hospital Clínico Universitario de Santiago de Compostela

Lucía Ferreiro ( $\sim$ Iferfer7@gmail.com )

Hospital Clínico Universitario de Santiago de Compostela https://orcid.org/0000-0002-9023-0429

\section{Research Article}

Keywords: Covid-19; pneumonia; severity; predictive model

Posted Date: June 5th, 2020

DOI: https://doi.org/10.21203/rs.3.rs-33234/v1

License: (c) (1) This work is licensed under a Creative Commons Attribution 4.0 International License. Read Full License 


\section{Abstract}

The prognosis of a patient with Covid-19 pneumonia is uncertain. Our objective was to establish a predictive model of disease progression to facilitate early decision-making.

A retrospective study was performed of patients admitted with Covid-19 pneumonia, classified as severe (admission to the intensive care unit, mechanic invasive ventilation, or death) or non-severe. A predictive model based on clinical, analytical, and radiological parameters was built. The probability of progression to severe disease was estimated by logistic regression analysis. Calibration and discrimination (receiver operating characteristics curves and AUC) were assessed to determine model performance.

During the study period 1,152 patients presented with Covid-19 infection, of whom 229 (19.9\%) were admitted for pneumonia. During hospitalization, 51 (22.3\%) progressed to severe disease, of whom 26 required ICU care (11.4); 17 (7.4\%) underwent invasive mechanical ventilation, and 32 (14\%) died of any cause. Five predictors determined within 24 hours of admission were identified: Diabetes, Age, Lymphocyte count, $\mathrm{SaO}_{2}$, and $\mathrm{pH}$ (DALSH score). The prediction model showed a good clinical performance, including discrimination (AUC $0.87 \mathrm{Cl} 0.81,0.92$ ) and calibration (Brier score $=0.11$ ). In total, $0 \%, 12 \%$, and $50 \%$ of patients with severity risk scores $\leq 5 \%, 6-25 \%$, and $>25 \%$ exhibited disease progression, respectively.

A simple risk score based on five factors predicts disease progression and facilitates early decision-making according to prognosis.

\section{Introduction}

The first cases of pneumonia of unknown origin were detected in Wuhan (Hubei, China) in early December 2019 ${ }^{1}$. On 7 January 2020, Chinese scientists isolated a novel coronavirus that was named as severe acute respiratory syndrome coronavirus 2 (SARS-CoV-2), and the relevant disease was called coronavirus-2019 disease (Covid-19) ${ }^{2}$. Since then, the dramatic increase in cases has posed numerous challenges to even the most sophisticated and advanced health systems, which led the World Health Organization (WHO) to declare the outbreak a pandemic in March 20203. To date, health systems worldwide have experienced an exponential increase in hospitalizations and admissions to intensive care units (ICUs) associated with Covid-194.

Covid-19 can cause a wide variety of symptoms ranging from asymptomatic infection to life-threatening complications such as acute respiratory distress, multi-organic failure, and death ${ }^{1,5-7}$. Some studies have evidenced that older patients with comorbidities (including arterial hypertension, cardio-respiratory disease or diabetes) ${ }^{6}$ and patients with more elevated levels of cytokines in blood ${ }^{1}$ are the ones at a higher risk for experiencing severe complications $\mathbf{s}^{8,9}$.

At this time, there are no specific vaccines or treatments for Covid-19. Accurate diagnosis and prognosis of the disease are crucial to alleviating the burden on the health system while the best care possible is provided to patients. A predictive model that combines several variables or parameters to estimate the risk for a poor outcome would help the clinician to estimate the prognosis of patients when limited healthcare resources 
are available. Thus, early identification of patients at risk of serious complications is clinically relevant ${ }^{10} \mathrm{~A}$ recent systematic literature review found ten prognostic models for predicting mortality or progression to severe disease, but only a study involved patients from countries other than China, and all studies had been categorized as being at a high risk of bias ${ }^{11}$.

Therefore, the aim of this study was to develop and validate a prognostic model to identify inpatients with Covid-19 pneumonia at a greater risk for developing severe/critical complications, including death.

\section{Methods}

\section{Source of data}

Data were collected from the medical reports of patients diagnosed with Covid-19 and admitted to the Complejo Hospitalario Universitario of Santiago de Compostela in Spain, a hospital with over 1000 beds, from March 12, 2020 (date of first Covid-19 diagnosis) to April 11. The study was conducted in accordance with the guidelines of the Declaration of Helsinki and the principles of good clinical practice and was approved by the Institutional Review Board (IRB) of the Galician Health Service on April 3, 2020 (\#2020/194). Informed consent forms were waived by the IRB.

A confirmed case of Covid-19 was defined as a positive result in the reverse transcription polymerase chain reaction (RT-PCR) test on samples obtained from nasal or throat swabs performed in accordance with WHO protocol $^{12}$. Only laboratory-confirmed cases were considered for analysis. Patients with uncomplicated disease, with symptoms of upper airway infection, headache, myalgia, anosmia, dysgeusia or anorexia, but with an $\mathrm{SaO}_{2}>95 \%$ and a respiratory rate $<25$ breaths/minute, all considered as low-risk ( $<60$ years of age and without comorbidities), and high-risk patients (>60 years and comorbidities) were monitored as follows: 1) At home by the TELEA system, a home monitoring platform that allows to monitor respiratory and heart rate, temperature, and $\mathrm{SaO}_{2} ; 2$ ) patients without an Internet connection at home were monitored via 2-3 telephone calls daily. If the clinical status of the patient deteriorated, a physician contacted them to decide where hospitalization was required or not; 3) previously-institutionalized patients or those without enough assistance at home were transferred to a socio-health center adapted as a hospital. All patients diagnosed with Covid-19 pneumonia were hospitalized.

All patients with Covid-19 pneumonia were eligible for inclusion. Pneumonia was defined as an acute respiratory disorder characterized by cough, at least a novel condensation on chest X-ray and fever for four days or more or dyspnea/tachypnea ${ }^{13}$. Exclusion criteria were simultaneous infection by another germ or in other organ. Fever was defined as an axillary temperature $\geq 37.5^{\circ} \mathrm{C}$. Diagnosis of acute respiratory distress syndrome (ARDS) was established in accordance by the Berlin definition ${ }^{14}$.

The data extracted from the medical history of patients included symptoms, clinical signs, and laboratory test and radiological results at admission (+1 day). The comorbidities considered were arterial hypertension, diabetes mellitus, chronic obstructive pulmonary disease, other respiratory diseases, kidney and liver disease, heart failure, ischemic heart disease, heart valve surgery, active neoplasm, systemic disease, and 
psoriasis. Previous use of drugs such as angiotensin-converting enzyme inhibitors, angiotensin II receptor antagonists, statins, corticosteroids, immunosuppressants, antiplatelet agents, and anticoagulants were recorded. The totality of laboratory tests were performed as a function of the clinical care needs of the patients. Determinations in blood included a complete hemogram, coagulation tests (including D-dimer), an evaluation of liver and kidney function, and determination of electrolytes, C-reactive protein (CRP), procalcitonin, lactate dehydrogenase (LDH), creatine kinase, ferritin, and interleukin 6. Covid-19 was considered severe and the patient was candidate to ICU admission if required mechanical ventilation or had a fraction of inspired oxygen $\left(\mathrm{FiO}_{2}\right)$ of at least $60 \%$ or more ${ }^{15}$. Radiological anomalies were collected from reports of the Unit of Radiology.

Outcomes of interest were death from any cause, use of mechanic invasive ventilation, or ICU stay.

\section{Statistical analysis}

Multiple imputation was used to impute missing data by creating 100 datasets. Missing values were predicted on the basis of all other predictors considered for assessing outcomes ${ }^{16}$. For each of them, 250 bootstrap datasets were generated, and backwards feature selection with the Akaike Information Criterion was performed on every set ${ }^{17}$.

The predictors returned by this procedure in $70 \%$ of datasets were selected for the final model, and their regression coefficients were calculated according to "Rubin's Rules"18. We also studied the possible nonlinear effect of each predictor on the outcome by means of Generalized Additive models (GAM) using splines ${ }^{17}$. Results are presented as Odds Ratio (OR) with $95 \%$ confidence intervals (Cl). The Nagelkerke $\mathrm{R}^{2}$ was used to calculate the proportion of variance in clinical outcomes that could be explained by the selected predictors. The different aspects of model performance were studied, including calibration and discrimination ${ }^{19}$. Calibration was assessed using the Brier score, and by plotting the non-parametric estimate of the association between the observed frequencies and the predicted probabilities. The receiver operating characteristics (ROC) curves (and the correspondent area under the ROC curve-AUC) were calculated to test for discrimination. To correct optimism, internal validation was performed using the bootstrap procedure. The procedure was repeated in each imputed dataset, and the average estimates for the AUC, the Brier Score, and the Nagelkerke $\mathrm{R}^{2}$ were extracted to assess discrimination, calibration, and overall fit, respectively ${ }^{20}$. The final model was selected to derive a score for clinical use and a nomogram was created. Criteria for this selection included both discriminant ability (defined by the AUC) and model simplicity. All statistical analyses were carried out in R version 3.5.1 using the mice rms and psfmi packages). These packages are freely available at http://cran.r-project.org. The analysis conforms to TRIPOD reporting standards ${ }^{21}$.

\section{Results}

During the study period, 1,152 patients were infected by Covid-19, of whom $229(19.9 \%)$ were admitted for pneumonia. None of the hospitalized patients were lost to follow-up. During hospitalization, 51 (22.3\%) 
cases progressed to severe disease (Figure 1), of whom 26 (11.4\%) needed intensive care, $17(7.4 \%)$ underwent invasive mechanical ventilation, and $32(14 \%)$ died of any cause. The majority of patients (90\%) received antibiotic therapy and hydroxychloroquine, and $83.8 \%$ received lopinavir/ritonavir. Additionally, 30\% were given systemic glucocorticoids, and $8.3 \%$ were administered tocilizumab.

\section{Clinical characteristics}

Baseline demographic, clinical, and laboratory data are presented in Table 1. The most common symptoms at onset of illness were cough (77.3\%), fever (75.5\%), and dyspnea (52.8\%). Patients with severe disease were significantly older than those with nonsevere disease and were more likely to have higher systolic blood pressure levels $(p=0.003)$, and lower $\mathrm{SaO}_{2}$ concentrations $(p<0.001)$. The presence of comorbidities such as diabetes, heart failure, and chronic kidney disease was significantly higher in patients who progressed to severe disease. No statistically significant differences were observed between the two groups in main symptoms, although slightly more patients in the severe group manifested confusion $(p=0.025)$.

Table 1. Clinical characteristics of the study patients 


\begin{tabular}{|c|c|c|c|c|c|}
\hline Characteristics & \begin{tabular}{l}
\multicolumn{2}{c}{ All patients } \\
Missing $\quad(\mathrm{n}=$ \\
229)
\end{tabular} & $\begin{array}{r}\text { Sever } \\
\text { yes }(n=\end{array}$ & no $(n=$ & $\begin{array}{l}\text { Odds Ratio } \\
\text { (95\%CI) }\end{array}$ & $p$ value \\
\hline $\begin{array}{l}\text { Age, yr } \\
\text { Male sex } \\
\text { Temperature } \geq 37.5^{\circ} \mathrm{C} \\
\text { Systolic blood pressure, } \mathrm{mmHg} \\
\text { Diastolic blood pressure, } \mathrm{mmHg} \\
\text { Heart rate, beats/min } \\
\mathrm{SaO}_{2}\end{array}$ & $\begin{array}{lc}0 & 68(56, \\
75) & \\
0 & 139 \\
(60.7) & \\
1 & 82 \\
(36.0) & \\
0 & 130(118, \\
140) & \\
0 & 74(66, \\
80) & \\
1 & 83(74, \\
94) & \\
8 & 94(92, \\
96) & \\
\end{array}$ & $\begin{array}{c}74(68,83) \\
40(78.4) \\
23(45.1) \\
134(120 \\
151) \\
75(66,82) \\
86(74,96) \\
92(88,95)\end{array}$ & $\begin{array}{c}65(55,73) \\
99(55.6) \\
59(33.3) \\
129(118 \\
139) \\
74(66,80) \\
81(75,91) \\
95(93,96)\end{array}$ & $\begin{array}{c}1.06(1.03, \\
1.09) \\
2.90(1.40, \\
6.02) \\
1.64(0.87 \\
3.10) \\
1.02(1.01 \\
1.04) \\
1.01(0.98 \\
1.04) \\
1.01(0.99 \\
1.04) \\
0.87(0.81 \\
0.93)\end{array}$ & $\begin{array}{l}0.000 \\
0.004 \\
0.125 \\
0.003 \\
0.521 \\
0.246 \\
0.000\end{array}$ \\
\hline $\begin{array}{l}\text { Symptoms } \\
\text { Fever } \\
\text { Cough } \\
\text { Shortness of breath } \\
\text { Thoracic pain } \\
\text { Diarrhea } \\
\text { Anosmia } \\
\text { Dysgeusia } \\
\text { Confusion }\end{array}$ & $\begin{array}{l}0 \\
(77.3) \\
0 \\
(75.5) \\
0 \\
(52.8) \\
0 \\
(9.2) \\
0 \\
(24.9) \\
6 \\
(7.4) \\
7 \\
(10.9) \\
0 \\
(3.9) \\
\end{array}$ & $\begin{aligned} 40 & (78.4) \\
37 & (72.5) \\
34 & (66.7) \\
2 & (3.9) \\
10 & (19.6) \\
2 & (4.0) \\
3 & (6.0) \\
5 & (9.8)\end{aligned}$ & $\begin{array}{c}137(77.0) \\
136(76.4) \\
87(48.9) \\
19(10.7) \\
47(26.4) \\
15(8.7) \\
22(12.8) \\
4(2.2)\end{array}$ & $\begin{array}{c}1.09(0.51 \\
2.31) \\
0.82(0.40 \\
1.65) \\
2.09(1.09 \\
4.02) \\
0.34(0.08 \\
1.52) \\
0.68(0.32 \\
1.46) \\
0.44(0.10 \\
1.99) \\
0.44(0.12 \\
1.52) \\
4.73(1.22 \\
18.3) \\
\end{array}$ & $\begin{array}{l}0.826 \\
0.573 \\
0.027 \\
0.158 \\
0.324 \\
0.285 \\
0.192 \\
0.025\end{array}$ \\
\hline $\begin{array}{l}\text { Treatment } \\
\text { Angiotensin-converting enzyme } \\
\text { inhibitors } \\
\text { Angiotensin II receptor } \\
\text { antagonists } \\
\text { Statins } \\
\text { Corticosteroids } \\
\text { Immunosupressors } \\
\text { Anticoagulants } \\
\text { Antiplatelet agents }\end{array}$ & $\begin{array}{l}0 \\
(9.2) \\
0 \\
(24.0) \\
0 \\
(40.2) \\
0 \\
(8.3) \\
0 \\
(9.6) \\
0 \\
(8.7) \\
0 \\
(12.2) \\
\end{array}$ & $\begin{aligned} 4 & (7.8) \\
15 & (29.4) \\
23 & (45.1) \\
3 & (5.9) \\
1 & (2.0) \\
13 & (5.5) \\
5 & (9.8)\end{aligned}$ & $\begin{array}{c}17(9.6) \\
40(22.5) \\
69(38.8) \\
16(9.0) \\
14(7.9) \\
7(3.9) \\
23(12.9)\end{array}$ & $\begin{array}{c}0.81(0.26, \\
2.51) \\
1.44(0.72, \\
2.89) \\
1.30(0.69 \\
2.43) \\
0.63(0.18, \\
2.26) \\
0.23(0.03, \\
1.86) \\
8.36(3.12, \\
22.3) \\
0.73(0.26 \\
2.03) \\
\end{array}$ & $\begin{array}{l}0.710 \\
0.308 \\
0.417 \\
0.482 \\
0.166 \\
0.000 \\
0.550\end{array}$ \\
\hline $\begin{array}{l}\text { Medical history } \\
\text { Chronic obstructive pulmonary } \\
\text { disease } \\
\text { Arterial hypertension } \\
\text { Diabetes mellitus } \\
\text { Chronic renal disease } \\
\text { Coronary heart disease } \\
\text { Heart failure } \\
\text { Cancer } \\
\text { Systemic disease } \\
\text { Pulmonary disease }\end{array}$ & $\begin{array}{l}0 \\
(7.4) \\
O \\
(44.1) \\
O \\
(21.8) \\
0 \\
(9.2) \\
0 \\
(7.4) \\
O \\
(6.1)\end{array}$ & $\begin{aligned} 7 & (13.7) \\
27 & (52.9) \\
24 & (47.1) \\
9 & (17.6) \\
5 & (9.8) \\
10 & (19.6) \\
5 & (9.8) \\
2 & (3.9) \\
10 & (19.6)\end{aligned}$ & $\begin{array}{c}10(5.6) \\
74(41.6) \\
26(14.6) \\
12(6.7) \\
12(6.7) \\
4(2.2) \\
7(3.9) \\
17(9.6) \\
24(13.6)\end{array}$ & $\begin{array}{c}2.67(0.96 \\
7.42) \\
1.58(0.85 \\
2.96) \\
5.20(2.61 \\
10.3) \\
2.96(1.17 \\
7.50) \\
1.50(0.50 \\
4.49) \\
10.6(3.25 \\
35.5)\end{array}$ & $\begin{array}{l}0.059 \\
0.151 \\
0.000 \\
0.022 \\
0.465 \\
0.000 \\
0.109 \\
0.214 \\
0.288\end{array}$ \\
\hline
\end{tabular}




\begin{tabular}{|c|c|c|}
\hline $\begin{array}{l}0 \\
(5.2) \\
0 \\
(8.3) \\
1 \\
(14.8)\end{array}$ & $\begin{array}{r}12 \\
19 \\
34\end{array}$ & $\begin{array}{c}2.66(0.81, \\
8.75) \\
0.39(0.09, \\
1.73) \\
1.55(0.69 \\
3.51)\end{array}$ \\
\hline
\end{tabular}

Data are n (\%). 95\%CI, 95\% Confidence Interval

On admission, patients who progressed to severe disease had a lower baseline lymphocyte and platelet count, lower levels of hemoglobin, and higher levels of neutrophils, serum creatinine, urea, CRP, and interleukin-6 (all p <0.01) (Table 2). Abnormalities on chest X-ray images were detected in all patients. Most than half of patients (57.2\%) had bilateral pneumonia (Table 3 ). The most common findings in patients who progressed to severe disease were bilateral multiple lobular and subsegmental areas of consolidation. Table 3 shows a comparison of gasometric parameters between the two groups by level of severity.

Table 2. Laboratory characteristics of the study patients on admission 


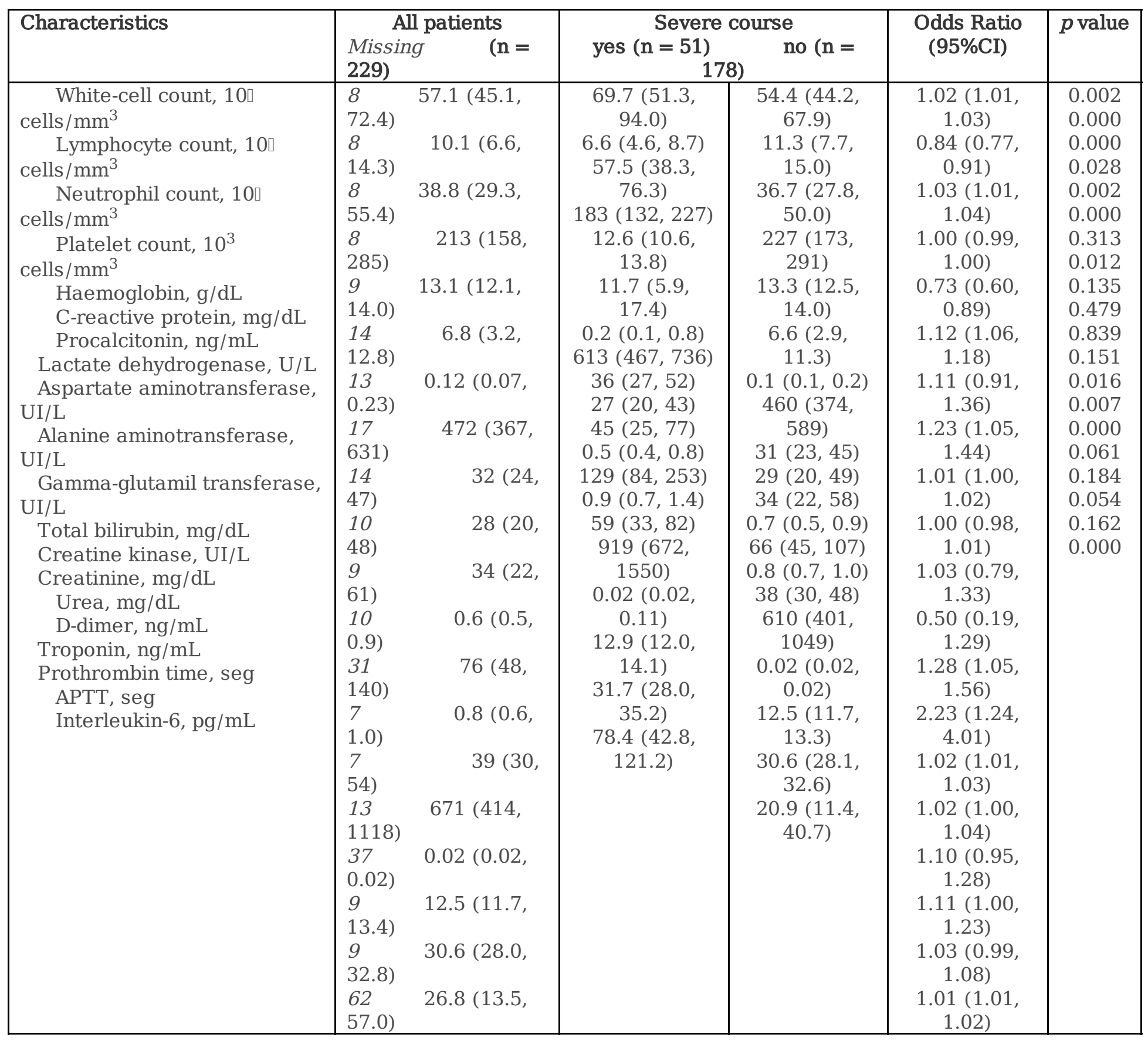

Data are median (IQR). 95\%CI, 95\% Confidence Interval; APTT, activated partial thromboplastin time

Table 3. Radiological and gasometric characteristics on admission 


\begin{tabular}{|c|c|c|c|c|c|}
\hline & \multirow{2}{*}{\begin{tabular}{c}
\multicolumn{2}{c}{ All patients } \\
Missing $\quad(\mathrm{n}=229)$
\end{tabular}} & \multicolumn{2}{|c|}{ Severe course } & \multirow{2}{*}{$\begin{array}{l}\text { Odds Ratio } \\
(95 \% \mathrm{CI})\end{array}$} & \multirow[t]{2}{*}{$p$ value } \\
\hline & & yes $(n=51)$ & no $(n=178)$ & & \\
\hline $\begin{array}{l}\text { Radiologic } \\
\text { Unilateral consolidation } \\
\text { Bilateral consolidation } \\
\text { Interstitial } \\
\text { abnormalities } \\
\text { Consolidation + } \\
\text { interstitial }\end{array}$ & $\begin{array}{ll}98 & (42.8) \\
81 & (35.4) \\
26 & (11.3) \\
24 & (10.5)\end{array}$ & $\begin{aligned} 12 & (23.5) \\
28 & (54.9) \\
5 & (9.8) \\
6 & (11.8)\end{aligned}$ & $\begin{array}{l}86(48.3) \\
53(29.8) \\
21(11.8) \\
18(10.1)\end{array}$ & $\begin{array}{c}\text { Reference } \\
3.7(1.7,8.1) \\
1.7(0.5,5.4) \\
2.4(0.8,7.2)\end{array}$ & $\begin{array}{c}- \\
0.005 \\
0.361 \\
0.122\end{array}$ \\
\hline $\begin{array}{l}\text { Gasometry } \\
\mathrm{FiO}_{2} \\
\mathrm{pH} \\
\mathrm{PaCO}_{2}, \mathrm{~mm} \mathrm{Hg} \\
\mathrm{PaO}_{2}, \mathrm{~mm} \mathrm{Hg} \\
\mathrm{HCO}_{3^{-}}, \mathrm{mmol} / \mathrm{L} \\
\mathrm{SaO}_{2}, \% \\
\quad \mathrm{PaO}_{2} / \mathrm{FiO}_{2} \text { ratio, } \mathrm{mm} \mathrm{Hg} \\
\mathrm{SaO}_{2} / \mathrm{FiO}_{2} \text { ratio }\end{array}$ & 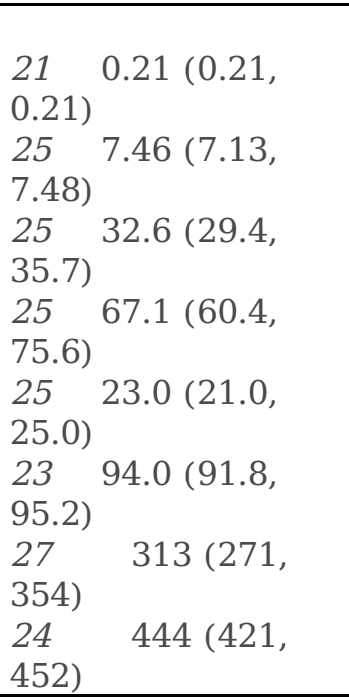 & $\begin{array}{c}0.21(0.21 \\
0.21) \\
7.47(7.41 \\
7.49) \\
31.3(28.5, \\
36.0) \\
60.0(51.8, \\
67.8) \\
22.2(20.0, \\
24.1) \\
91.4(86.0, \\
94.0) \\
262(227,300) \\
423(383,441)\end{array}$ & $\begin{array}{c}0.21(0.21 \\
0.21) \\
7.46(7.43 \\
7.48) \\
32.8(30.0 \\
35.6) \\
69.7(63.1 \\
76.5) \\
23.0(21.0 \\
25.0) \\
94.0(92.8 \\
95.4) \\
326(290,360) \\
447(433,452)\end{array}$ & $\begin{array}{c}50(0.2,12900) \\
0.57(0.00 \\
680) \\
0.97(0.91 \\
1.03) \\
0.95(0.93 \\
0.98) \\
0.92(0.83 \\
1.02) \\
0.85(0.79 \\
0.92) \\
0.99(0.98 \\
0.99) \\
0.99(0.99 \\
1.00)\end{array}$ & $\begin{array}{l}0.166 \\
0.877 \\
0.347 \\
0.000 \\
0.117 \\
0.000 \\
0.000 \\
0.001\end{array}$ \\
\hline
\end{tabular}

Data are n (\%) or median (IQR). 95\%CI, 95\% Confidence Interval

\section{Multivariate Prediction Models}

A regression model was built based on the aforementioned clinical, laboratory, gasometric, and radiographic data to predict the risk of progression to severe/critical disease. Five predictors were identified: Diabetes, Age, Lymphocyte count, $\mathrm{SaO}_{2}$, and pH (DALSH score, Nagelkerke $\mathrm{R}^{2}$ 0.45, Table 4). As shown in Figure 2 , whereas risk increases linearly with age and decreases as $\mathrm{SaO}_{2}$ diminishes, the relationship with leukocyte count and $\mathrm{pH}$ is not linear.

Table 4. Multivariate logistic regression analysis.

\begin{tabular}{|l|c|c|c|c|}
\hline & $\beta$ & $\mathrm{SE}(\beta)$ & OR (95\%CI) & $\boldsymbol{p}$ value \\
\hline Intercept & 87.4549 & & & \\
Diabetes, yes & 1.4963 & 0.4480 & $4.46(1.86,10.74)$ & 0.0008 \\
Age, yr & 0.0508 & 0.0171 & $1.05(1.02,1.09)$ & 0.0030 \\
Lymphocyte count & & & & \\
$\quad$ rcs (1) & -0.0036 & 0.0011 & see Figure 2 & 0.0011 \\
rcs (1') & 0.0038 & 0.0017 & & 0.0017 \\
$\mathrm{SaO}_{2}, \%$ & -0.1233 & 0.0434 & $0.88(0.81,0.96)$ & 0.0046 \\
pH & -10.6378 & 7.7831 & see Figure 2 & 0.1717 \\
$\quad$ rcs (1) & 22.0366 & 9.5570 & & 0.0212 \\
$\quad$ rcs (1') & \multicolumn{4}{|c|}{ Brier score 0.11 } \\
\hline AUC 0.87 & $\mathrm{R}^{2} 0.44$ \\
AUC corrected 0.85 & $\mathrm{R}^{2}$ corrected 0.38 & Brier score corrected 0.13 \\
\hline
\end{tabular}

$\beta$ indicates coefficient; SE, standard error; 95\%CI, 95\% confidence interval; 
rcs, restricted cubic splines (to interpret, see Figure 2); AUC, Area under the ROC curve

The receiver operating characteristic curve for this combination of predictors (Figure 3 ) confirmed its good clinical performance (AUC $0.87 \mathrm{Cl} 0.81,0.92$ ). The AUC was higher than that obtained with the CURB-65 (AUC $0.73 \mathrm{CI} 0.68,0.78$ ). The DALSH score showed an acceptable calibration (Brier score $=0.11$, see supplementary material, Figure $1 S$ ). After correcting optimism by bootstrapping, Nagelkerke $\mathrm{R}^{2}, \mathrm{AUC}$, and Brier score were $0.38,0.85$, and 0.13 , respectively.

Figure 2S (see supplementary material) illustrates a method to estimate the risk of progression to severe disease based on an overall score calculated by the sum of the individual scores obtained in the five variables of the model.

Table 5 shows the individual score of each of the DALSH predictors. The total score indicates the estimated individual risk of severity of each patient. Scores above 80 points mean a $>10 \%$ risk of progression to severe disease, which is attained by all patients $>70$ years with diabetes. If patients also exhibit a $\mathrm{SaO}_{2} \leq 90 \%$, the risk raises to $20 \%$; if patients also have a $\leq 1,000$ lymphocyte count, the risk of progression to severe disease reaches $50 \%$. As many as $30 \%$ of patients (69) had a $\leq 5 \%$ risk of progression (arbitrarily considered as low risk); 89 (39\%) had a risk of 6-25\% (intermediate risk), and 71 patients (31\%) had a >25\% risk (high risk). No patients with a DALSH score $<66$ points (low risk) progressed to severe disease (ICU admission, need for invasive mechanical ventilation, or death); whereas $12 \%$ of patients with a DALSH score of $66-100$ points (intermediate risk) progressed to severe disease; finally, $50 \%$ of patients with a DALSH score $>100$ points progressed to severe disease. Half of patients identified as high-risk had a mean age of 74 years. Notably, low-risk patients had a mean age of 54 years and none had diabetes.

Table 5. The DALSH score calculation

\begin{tabular}{|c|c|c|c|c|c|c|c|c|c|c|c|c|}
\hline DM & Points & $\begin{array}{l}\text { Age, } \\
\text { yr }\end{array}$ & Points & $\begin{array}{l}\text { Lymphocytes, } \\
\text { n }\end{array}$ & Points & $\begin{array}{l}\mathrm{SaO}_{2}, \\
\%\end{array}$ & Points & $\mathrm{pH}$ & Points & $\begin{array}{l}\text { Total } \\
\text { points }\end{array}$ & $\begin{array}{l}\text { Severity } \\
\text { risk }\end{array}$ & Levels \\
\hline No & 0 & 20 & 0 & 150 & 62 & 60 & 100 & 7.30 & 24 & 18 & 0.005 & \\
\hline \multirow[t]{9}{*}{ Yes } & 31 & 30 & 10 & 250 & 55 & 65 & 86 & 7.35 & 15 & 32 & 0.010 & Low \\
\hline & & 40 & 20 & 500 & 39 & 70 & 73 & 7.40 & 5 & 66 & 0.050 & \\
\hline & & 50 & 30 & 750 & 23 & 75 & 59 & 7.45 & 0 & 81 & 0.100 & \\
\hline & & 60 & 40 & 1000 & 10 & 80 & 46 & 7.50 & 14 & 101 & 0.250 & Medium \\
\hline & & 70 & 50 & 1500 & 0 & 85 & 32 & 7.55 & 37 & 125 & 0.500 & \multirow{5}{*}{ High } \\
\hline & & 80 & 59 & 2000 & 1 & 90 & 19 & 7.60 & 60 & 142 & 0.700 & \\
\hline & & 90 & 69 & 3000 & 7 & 95 & 8 & 7.65 & 82 & 170 & 0.900 & \\
\hline & & 100 & 79 & 4000 & 13 & 100 & 0 & & & 185 & 0.950 & \\
\hline & & 110 & 89 & & & & & & & 218 & 0.990 & \\
\hline
\end{tabular}

DALSH, diabetes, age, lymphocytes, saturation, pH; DM, diabetes mellitus; yr, years

\section{Discussion}


Given the high transmission rate, potential severity of symptoms, and scarcity of resources that may result from the Covid-19 pandemic, predicting the course of coronavirus is crucial to guaranteeing that patients receive the best care possible. In this study we derived and validated a clinical prediction rule for the prognosis of hospitalized patients with Covid-19 pneumonia. Our results also show that the presence of diabetes, advanced age, lymphopenia, hypoxemia and $\mathrm{pH}$ alterations on admission were all associated with disease severity.

The course of Covid-19 pneumonia is uncertain and may lead to death. Predicting the course of Covid-19 pneumonia at 24 hours of admission based on clinical data is challenging but crucial. In a large number of cases, the disease can be controlled by closely monitoring the patient, but severely-ill patients will need aggressive treatment and intensive care. Predicting the course of the disease will enable the early adoption of a management approach in line with the estimated prognosis.

A multiplicity of studies have demonstrated that age is a relevant predictor of progression and mortality $5,7,22,23$, which is confirmed by the results of this study (OR $1.06 \mathrm{Cl} 1.03,1.09 ; \mathrm{p}=0.000)$. This may be explained by age-related effects on T- and B-cell function and the excessive production of type 2 cytokines. These alterations impair the body's ability to control viral replication and prolonged inflammatory response, thereby resulting in disease progression ${ }^{24}$.

Pneumonia may induce ischemia, endothelial dysfunction, and alterations in atherosclerotic plaques, which increases the short-term risk of cardiovascular events, especially in patients with previously known cardiovascular disease ${ }^{25}$. This may explain the fact that some studies - but not all ${ }^{1}$ - have revealed a relationship between previous cardiovascular disease and a poorer prognosis of Covid-195,7,22. In our study, patients with a previous diagnosis of heart failure were very likely to have a bad prognosis (OR $10.6 \mathrm{Cl} 3.25$, 35.5; $p=0.000$ ). Nevertheless, a relationship was not observed with ischemic heart disease. A variety of studies have established a relationship between diabetes and disease progression 5,7,22,23,26. In our case, Covid-19 pneumonia was five-fold more likely to progress to severe disease in patients with diabetes (OR $5.20 \mathrm{Cl} 2.61,10.35 ; \mathrm{p}=0.000$ ). However, no studies have been conducted to date to clarify the relationship between diabetes and Covid-19.

Although prognosis is favourable in most patients, those with Covid-19 pneumonia can develop dyspnea and hypoxemia. The underlying pathophysiology of disease progression seems to be that of severe ARDS. In these cases, the activation of alveolar macrophages by Covid-19 may trigger the release of powerful proinflammatory mediators and chemokines, the accumulation of neutrophils and monocytes, and the production of toxic mediators, which would lead to a loss of alveolar endothelial and epithelial barrier function, and ultimately induce alveolar and interstitial edema ${ }^{27}$. Analytical alterations identified in critical patients with Covid-19 pneumonia could be associated with adverse ARDS outcomes. This suggests that infection could induce cell-mediated immunity alterations, the activation of coagulation, and myocardial, hepatic or renal damage. In line with other publications, our study demonstrates that the risk of disease progression increases with alterations in $\mathrm{SaO}_{2}{ }^{7}$ (OR $\left.0.85 \mathrm{Cl} 0.79,0.92 ; \mathrm{p}=0.000\right)$; $\mathrm{LDH}^{5,6,7,9,22}(\mathrm{OR} 1.23 \mathrm{Cl}$ 1.05, 1.44; $p=0.012$ ); $\mathrm{CRP}^{6,7,9}$ (OR 1.12 Cl 1.06, 1.18; $\left.p=0.000\right) ;$ IL-6 ${ }^{6}$ (OR 1.01 Cl 1.01, 1.02; $p=0.000$ ); and 
lymphocyte count $\mathrm{f}^{5,6,7,9,22}$ (OR $0.84 \mathrm{Cl} 0.77,0.91 ; \mathrm{p}=0.000$ ), which are the most commonly used inflammation markers.

Our prognostic model is based on five predictors: diabetes, age, lymphocyte count, $\mathrm{SaO}_{2}$ and $\mathrm{pH}$, which we call the DALSH score. This score has demonstrated a good discrimination power (AUC $0.87 \mathrm{Cl} 0.81,0.92$ ). The DALSH score may be highly useful in clinical practice as these predictors can be easily determined in most settings and are usually recorded on admission. In addition, this score makes it possible to establish risk levels (even arbitrarily: $\leq 5 \%$, low; $6-25 \%$, intermediate and $>25 \%$ high) that may be useful to guide decision-making. Thus, a patient identified as low-risk is unlikely to experience disease progression; a relatively low number of patients identified as intermediate-risk will develop disease progression, and a large proportion of high-risk patients will experience disease progression. The cases observed in our series were $0 \%, 12 \%$ and $50 \%$, respectively. Determination of risk would help clinicians adopt the appropriate therapeutic measures.

Any $\mathrm{pH}$ alteration is associated with a higher risk for progression. $\mathrm{pH}$ decrease is probably related to hypercapnia secondary to alveolar hypoventilation, whereas its increase may be due to the presence of respiratory alkalosis with progressive hyperventilation caused by hypoxemia. The two settings can co-occur with disease progression (Figure 2D). A decrease in lymphocytes count causes an increase in OR, and the same occurs when it increases, although the effect is more subtle (Figure 2C). A recent systematic literature review on prognostic models for predicting mortality or progression to severe disease revealed that these models have good to excellent performance. However, only a study involved patients from countries other than China, and all studies had been categorized as being at a high risk of bias, mainly because the sample of control patients was not representative, patients who had not experienced the event of interest by the end of the study were excluded; and model overfitting. The performance estimated of these studies were rated to be optimistic and misleading ${ }^{11}$. Unlike some of those studies, in our study all patients were followed-up until discharge or death, and objective predictors were used. A major strength of our study is the high-quality data obtained for all predictors and the minimal rate of missing data.

This study has several limitations. First, since the model was developed in a single population, a major limitation is the lack of external validation. Second, sample size was not large enough to adequately develop a multivariate regression model in which 53 predictors were entered. For this reason, after multivariate analysis, we resampled the development sample using a bootstrapping technique. The purpose was to avoid overfitting and estimate the stability of the dataset. As a result, five variables were retained in the model.

In summary, our study identified five straightforward, objective predictors easily determined on admission, which are associated with progression to severe or critical state in hospitalized patients with Covid-19 pneumonia. A simple risk score based on these factors predicted disease progression and allowed us to adopt therapeutic measures in accordance with patient's prognosis from the very moment of diagnosis. Further studies should be conducted to validate the clinical value of the DALSH score for populations from other geographic areas.

\section{Declarations}


FUNDING. Carlos III Health Institute, Spain, Grant/Award Number: COV20/00404; Ministry of Economy and Competitiveness (SPAIN) and the European Regional Development Fund (FEDER).

Funding source had no involvement in study design, in the collection, analysis, and interpretation of data, in the writing of the report, and in the decision to submit the paper for publication.

Competing interests: The authors declare no competing interests.

\section{References}

1. Huang C, Wang Y, Li X, et al. Clinical features of patients infected with 2019 novel coronavirus in Wuhan, China. Lancet 2020;395:497-506.

2. Lu R, Zhao X, Li J, et al. Genomic characterization and epidemiology of 2019 novel coronavirus: implications for virus origins and receptor binding. Lancet 2020;395:565-74.

3. WHO Director-General's opening remarks at the media briefing on COVID-19: 11 March 2020. Published March 11, 2020. Accessed March 30, 2020. https://www.who.int/dg/speeches/detail/who-directorgeneral-s-opening-remarks-at-themedia-briefing-on-Covid-19--11-march-2020.

4. Grasselli G, Pesenti A, Cecconi M. Critical care utilization for the COVID-19 outbreak in Lombardy, Italy: early experience and forecast during an emergency response. Published online March 13, 2020. doi:10.1001/jama.2020.4031.

5. Wang D, Hu B, Hu C, et al. Clinical characteristics of 138 hospitalized patients with 2019 novel coronavirus-infected pneumonia in Wuhan, China. JAMA 2020; published online Feb 7. DOI:10.1001/jama.2020.1585.

6. Chen N, Zhou M, Dong X, et al. Epidemiological and clinical characteristics of 99 cases of 2019 novel coronavirus pneumonia in Wuhan, China: a descriptive study. Lancet 2020;395:507-13.

7. Guan W, Ni Z, Hu Y, et al. Clinical characteristics of coronavirus disease 2019 in China. N Engl J Med 2020; Feb 28. doi: 10.1056/NEJMoa2002032.

8. Weiss P, Murdoch DR. Clinical course and mortality risk of severe COVID-19. Lancet 2020; 395: 1014-5.

9. Wu C, Chen X, Cai Y, et al. Risk factors associated with acute respiratory distress syndrome and death in patients with coronavirus disease 2019 pneumonia in Wuhan, China. JAMA Intern Med 2020 March 13 (Epub ahead of print).

10. Phua J, Weng L, Ling L, et al. Intensive care management of coronavirus disease 2019 (COVID-19): challenges and recommendations. Lancet Respir Med 2020. https://doi.org/10.1016/S22132600(20)30161-2.

11. Wynants L, Van Calster B, Bonten MMJ, et al. Prediction models for diagnosis and prognosis of COVID19 infection: systematic review and critical appraisal. BMJ 2020;369:m1328

12. World Health Organization. Coronavirus disease (COVID-19) technical guidance: laboratory testing for 2019-nCoV in humans (https://www.who.int/ emergencies/ diseases/novel-coronavirus-2019/technicalguidance/laboratory-guidance). 
13. Woodhead M, Blasi F, Ewig S, et al. Guidelines for the management of adult lower respiratory tract infections - Summary. Clin Microbiol Infect 2011;17 (Suppl. 6):1-24.

14. The ARDS Definition Task Force. Acute Respiratory Distress Syndrome. The Berlin Definition. JAMA 2012;307:2526-33.

15. Domínguez-Cherit G, Lapinsky SE, Macias AE, et al. Critically ill patients with 2009 influenza $A(H 1 N 1)$ in Mexico. JAMA 2009;302:1880-7.

16. Van Buuren S. Flexible Imputation of Missing Data. 2nd Edition. Chapman \& Hall/CRC Interdisciplinary Statistics. Boca Raton, 2018.

17. Harrell. Regression Modeling Strategies. With Applications to Linear Models, Logistic and Ordinal Regression, and Survival Analysis. Springer, New York, 2015.

18. Heymans MW, van Buuren S, Knol DL, van Mechelen W, de Vet HCW. Variable selection under multiple imputation using the bootstrap in a prognostic study. BMC Med Res Methodol 2007; 7:33.

19. Steyerberg EW. Clinical Prediction Models. A Practical Approach to Development, Validation, and Updating. Springer, New York, 2009.

20. Marshall A, Altman DG, Holder RL, Royston P. Combining estimates of interest in prognostic modelling studies after multiple imputation: current practice and guidelines. BMC Med Res Methodol 2009; 9: 57.

21. Moons KG, Altman DG, Reitsma JB, et al. Transparent Reporting of a multivariable prediction model for Individual Prognosis Or Diagnosis (TRIPOD): explanation and elaboration. Ann Intern Med 2015; 162: W1-W73.

22. Zhou F, Yu T, Du R, et al. Clinical course and risk factors for mortality of adult inpatients with Covid-19 in Wuhan, China; a retrospective cohort study. Lancet 2020 published online March 9. https://doi.org/10.1016/ S0140-6736(20)30566-3.

23. Yang $X, Y u Y, X u$ J, et al. Clinical course and outcomes of critically ill patients with SARS-CoV-2 pneumonia in Wuhan, China: a single-centered, retrospective, observational study. Lancet 2020 pii: S2213-2600(20)30079-5. doi: 10.1016/S2213-2600(20)30079-5.

24. Opal SM, Girard TD, Ely EW. The immunopathogenesis of sepsis in elderly patients. Clin Infect Dis 2005;41(Suppl 7):S504-12.

25. Corrales-Medina VF, Musher DM, Shachkina S, Chirinos JA. Acute pneumonia and the cardiovascular system. 2013;381(9865):496-505.

26. Wu C, Chen X, Cai Y, et al. Risk factors associated with acute respiratory distress syndrome and death in patients with coronavirus disease 2019 pneumonia in Wuhan, China. JAMA 2020 doi:10.1001/jamainternmed.2020.0994.

27. Thompson BT, Chambers RC, Liu KD. Acute respiratory distress syndrome. N Engl J Med 2017;377:56272.

\section{Supplementary Information}

Figure S1. Calibration plot for the final model in imputed validation samples. Observed severity disease vs. predicted severity disease. Diagonal line indicates perfect calibration. 
Figure S2. Nomogram for prediction to severe disease among COVID-19 patients with pneumonia.

Instructions: Locate the patient's age on the (Age) axis. Draw a line straight upward to the point's axis to determine how many points toward the probability of progression to severe disease the patient receives for his/her Age. Repeat the process for each variable. Sum the points achieved for each of the predictors. Locate the final sum on the Total Points axis. Draw a line straight down to find the patient's probability of having severe disease.

DM = Diabetes Mellitus.

\section{Figures}

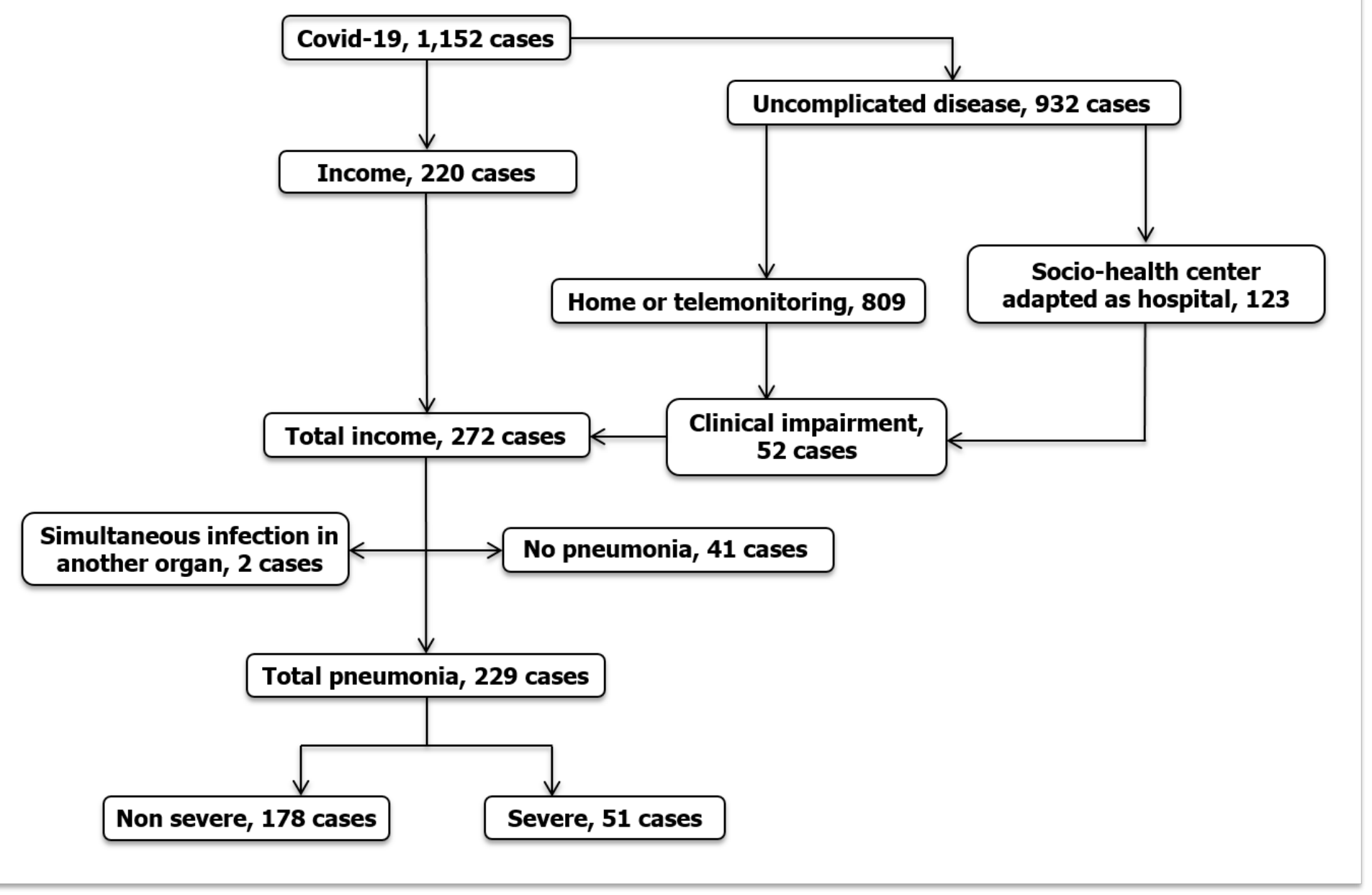

Figure 1

Flow chart for management of patients with Covid-2019 in health area of Santiago de Compostela. 

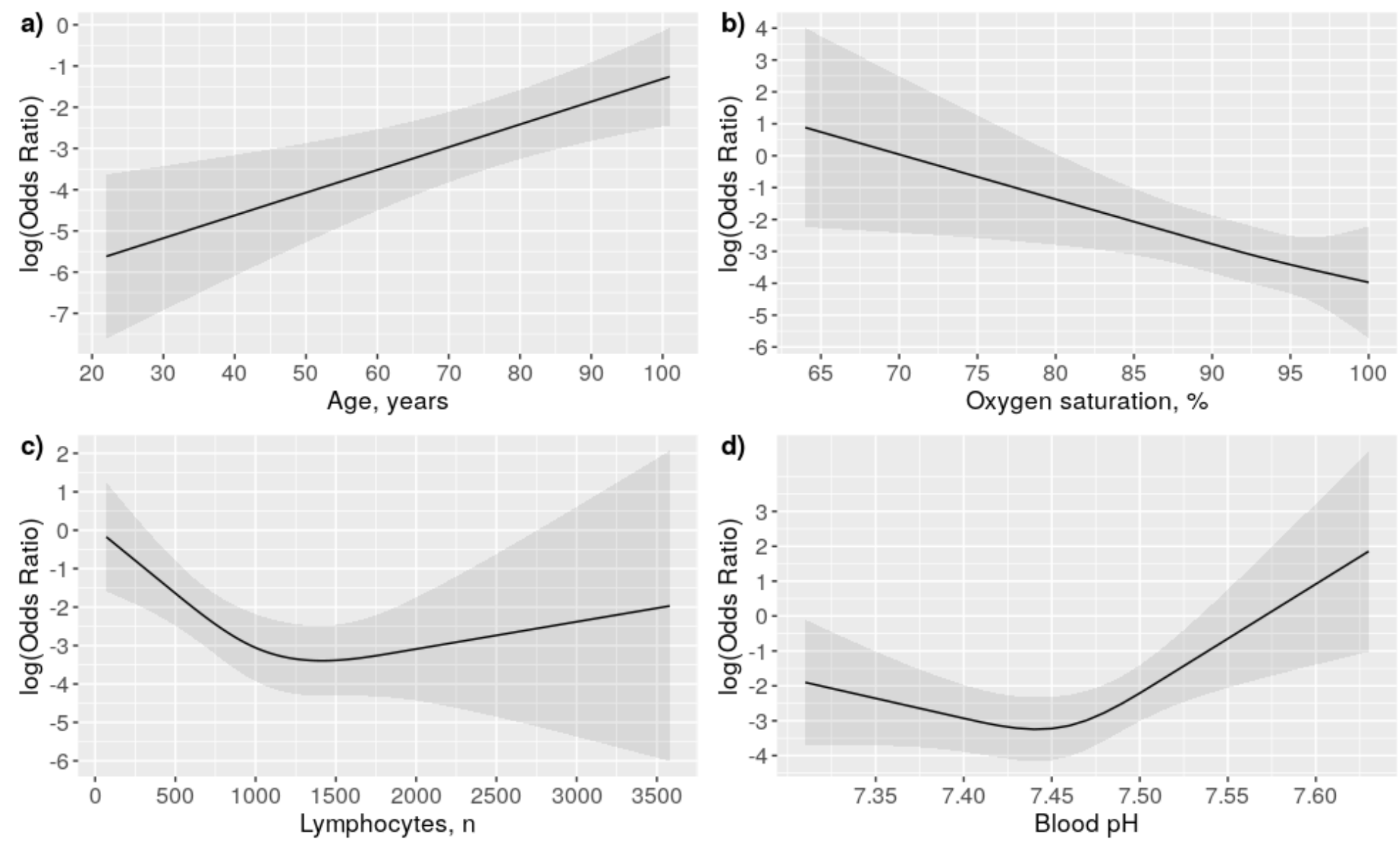

Figure 2

Effects of age, oxygen saturation, lymphocytes and $\mathrm{pH}$ on the risk for progression to severe disease. 


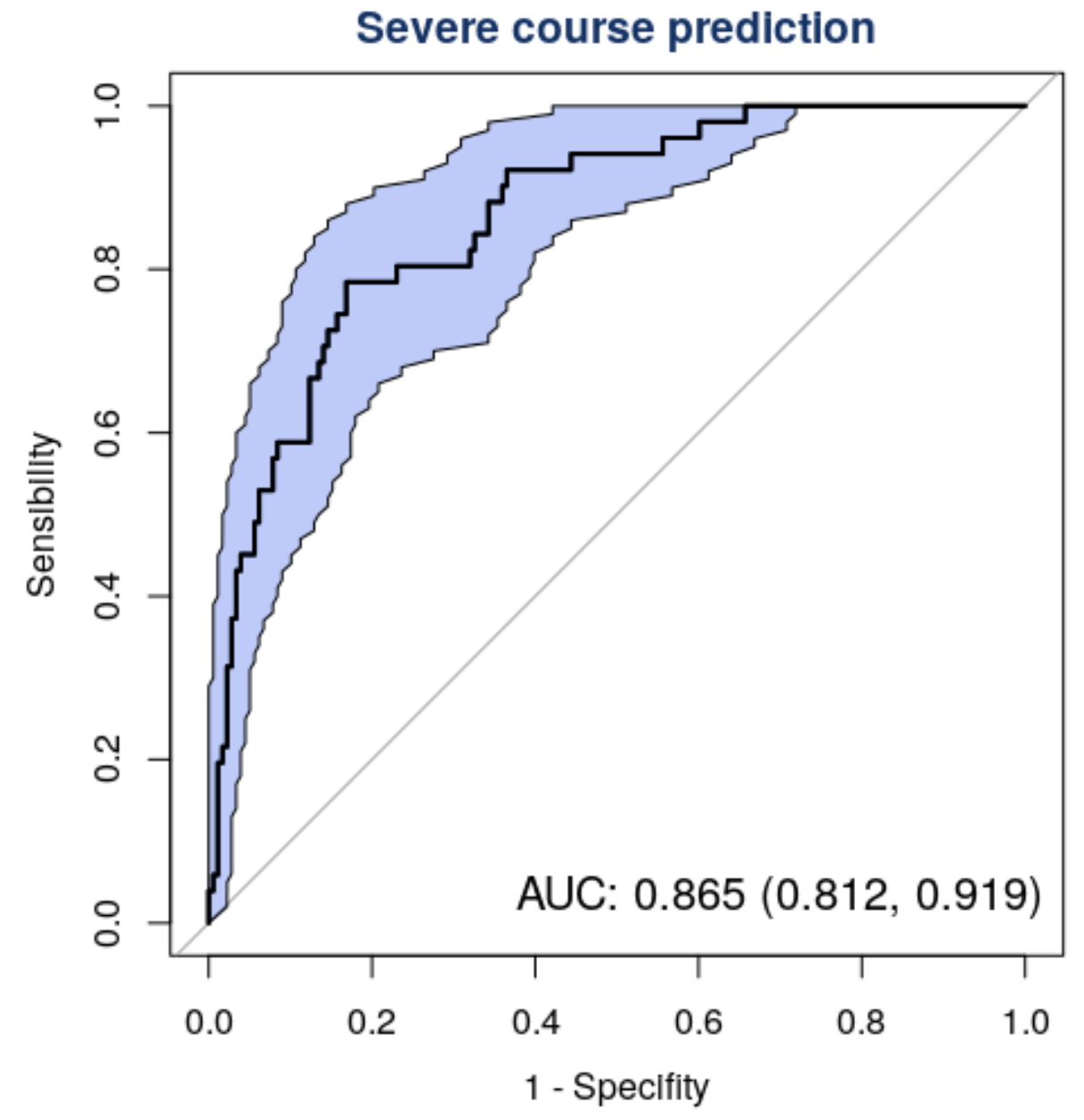

Figure 3

Receiver operating characteristic (ROC) curve for risk of severity in COVID-19 patients with pneumonia. Figures show Area under the Curve [AUC (95\% Confidence Interval)].

\section{Supplementary Files}

This is a list of supplementary files associated with this preprint. Click to download.

- Figure1S.tiff

- Figure2S.tiff 